\title{
Evaluation of Avena spp. Accessions for Resistance to Oat Stem Rust
}

\author{
J. Gold Steinberg, J. Mitchell Fetch, and T. G. Fetch, Jr., Cereal Research Centre, Agriculture and Agri-Food \\ Canada, 195 Dafoe Rd., Winnipeg, MB R3T 2M9 Canada
}

\begin{abstract}
Gold Steinberg, J., Mitchell Fetch, J., and Fetch, T. G., Jr. 2005. Evaluation of Avena spp. accessions for resistance to oat stem rust. Plant Dis. 89:521-525.

Oat stem rust, caused by Puccinia graminis f. sp. avenae, can cause significant yield losses in the eastern prairie region of western Canada. Currently, the predominant race of $P$. graminis $f$. sp. avenae in this region is NA67. Few genes confer resistance to NA67, and none are present in any oat cultivars registered for production in Canada. To detect lines exhibiting resistance to race NA67, we evaluated 9,978 accessions from 22 Avena spp. in field nurseries from 2001 to 2004. In all, 35 accessions were highly resistant and 12 were moderately resistant, comprised mostly of the species A. strigosa. Seventy-one accessions had an intermediate response, comprised mostly of A. abyssinica, A. barbata, A. sterilis, and A. vaviloviana. All other accessions $(9,860=$ $98.8 \%$ ) were susceptible to race NA67. Some highly resistant accessions were found to have been incorrectly classified previously as hexaploid species A. sativa or A. sterilis, and were confirmed by chromosome counts to be diploid or tetraploid. The most promising source of novel stem rust resistance is from the diploid species A. strigosa. Transfer of resistance from diploid and tetraploid species to A. sativa is very difficult, but the lines identified in this study should prove useful as new sources of resistance to oat stem rust.
\end{abstract}

Oat (Avena sativa) is one of the most important cereal crops grown worldwide. Annual world oat production is about 26 million metric tons ( $\mathrm{t}$ ), and Canada ranks second in production among all countries, at about 3.7 million $t$ (FAO statistics, 2003). Canada is the world's leading oat exporter, shipping nearly 1 million $\mathrm{t}$, primarily to the United States (1). About $90 \%$ of the oat production in Canada is in Saskatchewan, Manitoba, and Alberta (1). Production recently has decreased in Alberta and increased in Manitoba, likely from the abandonment of rail transportation subsidy, the proximity of Manitoba to the oat processors in the United States (22), and the higher yield potential in Manitoba. The higher yield potential in Manitoba and eastern Saskatchewan may be attributed, in part, to increased precipitation; however, this factor also increases

Corresponding author: T. G. Fetch, Jr.

E-mail: tfetch@agr.gc.ca

This is contribution no. 1889 of the Cereal Research Centre.

Support for this project was provided by the Western Grains Research Foundation.

Accepted for publication 5 December 2004.

DOI: 10.1094/PD-89-0521

(C) 2005 Department of Agriculture and AgriFood, Government of Canada the likelihood of plant diseases, which reduce yield and quality of the crop.

One of the most important diseases that can affect oat is stem rust, caused by $P u c$ cinia graminis f. sp. avenae. Severe epidemics of oat stem rust were frequent in North America in the early 1900s and also in western Canada in the 1940s (14). Recent epidemics in Manitoba and eastern Saskatchewan occurred in 1977 (13) and 2002 (5), and caused estimated yield losses of 35 and 5 to $10 \%$, respectively. The 2002 epidemic was attributed to race NA67, which was detected in western Canada for the first time in 1998 (18), and comprised $63 \%$ of the population found on cultivated oat in 2003 in Manitoba and Saskatchewan (6). Race NA67 is virulent to resistance genes $P g 1, P g 2, P g 3, P g 4, P g 8, P g 9$, $P g 13, P g 14, P g 15$, and $P g 17$, and avirulent to $P g 6, P g 10, P g 11, P g 12, P g 16$, and Pg-a (10; T. Fetch, unpublished). No oat cultivars currently registered for production in Canada possess genes with resistance to NA67 (7).

Breeding efforts to develop oat cultivars with resistance to NA67 are in progress at the Cereal Research Centre (CRC) in Winnipeg, but there are few resistance genes that are desirable to work with. For example, the gene Pg6 is highly resistant to NA67, but is in a diploid background (14). Transfer of resistance from lower ploidy levels (such as $P g 6$ ) to the hexaploid cultivated oat $A$. sativa is extremely difficult, due to cross-incompatibility and sterility in
$\mathrm{F}_{1}$ hybrids (20). $\mathrm{Pg} 10$ is intermediate in expression of resistance, and Pg12 is expressed only at the seedling stage (14). $P g 11$ is expressed only at the adult plant stage, and has been associated with weak straw, reduced yield, and progressive chlorosis as the plant ages (14). $P g 16$, which is derived from A. barbata, is linked to undesirable agronomic characteristics that lower yield (2) and is temperature sensitive (4). $P g-a$ is highly resistant to NA67, but is susceptible to race NA28, which sporadically has been detected in the Prairie region of Canada. New sources of stem rust resistance to race NA67 are desirable for the development of resistant cultivars for sustainable oat production in the eastern Prairie region of Canada and worldwide where stem rust is pandemic. The purpose of this investigation was to evaluate collections of Avena spp. germ plasm for resistance to race NA67. A preliminary report of this research has been published previously (7).

\section{MATERIALS AND METHODS}

Seed of 11,465 unique accessions from 22 Avena spp. was obtained from Dr. Harold Bockelman (United States Department of Agriculture-Agricultural Research Service, Aberdeen, ID), Dr. Axel Diedrichsen (Plant Genome Resources Canada, Saskatoon, SK, Canada), and Dr. Eviatar Nevo (University of Haifa, Israel). Avena spp. accessions were evaluated for their reaction to stem rust race NA67 in field nurseries established at University of Manitoba field plots in Winnipeg, MB in 2001 (6,860 entries), 2002 (3,361 entries), and 2003 (1,244 entries). Prior to planting of test entries, the oat cv. AC Assiniboia (susceptible to NA67) was sown using a Planet Jr. (Cole Manufacturing Co., Chicago, IL) as spreader rows to provide uniform rust inoculum across the test entries. Test entries were hand planted 10 to 14 days later in 1-m rows, perpendicular to the AC Assiniboia spreader rows. Resistant (Pg-a) and susceptible (AC Assiniboia) check lines ( 1 set per every 100 entries) and full sets ( 1 set per every 300 entries) of oat stem rust differential lines $(10,17)$ were randomly dispersed among the test entries to provide a measure of inoculum uniformity and to identify potential influence of exogenous inoculum. Nurseries were planted on land that was fallow the previ- 
ous season and hand weeded each year to control weed infestation, which could affect rust development. Spreader rows of AC Assiniboia were inoculated at the flag leaf growth stage (GS37) (23).

The isolate of race NA67 used in studies originally was collected from a cultivated oat grown in Manitoba during 2000 and phenotyped to race using oat stem rust differential lines $(10,17)$. The isolate was increased on the susceptible oat cv. Triple Crown in an isolated greenhouse room in the spring of 2001; urediniospores were collected and stored in glass tubes at $-80^{\circ} \mathrm{C}$ in an ultralow freezer until needed for inoculations. For field inoculations, urediniospores of NA67 were heat shocked at $50^{\circ} \mathrm{C}$ for $6 \mathrm{~min}$, then mixed with Bayol oil (Esso Canada, Toronto) to a concentration of $1.2 \mathrm{~g} \mathrm{liter}^{-1}$ and applied to plants using a Microfit Herbaflex sprayer (Micron, Herefordshire, UK) at a rate of 1 to 2 $\mathrm{ml} \mathrm{m}^{-1}$ of row. A second application was applied at the same rate 10 to 14 days later. Test entries were evaluated for percent severity (percentage of stem infected) and stem rust reaction $(\mathrm{R}=$ resistant, $\mathrm{MR}=$ moderately resistant, $\mathrm{I}=$ intermediate, and $\mathrm{S}=$ susceptible) at the heading stage (GS73) using a modified scale of Roelfs et al. (21).

Seed was collected when ripe from all accessions expressing resistance. The ploidy level of accessions classified as hexaploid or tetraploid was evaluated to confirm their chromosome number. Root tips from germinated seed were pretreated in ice water for $24 \mathrm{~h}$ immediately after collection, followed by fixation in $95 \%$ ethanol and glacial acetic acid (3:1) for 5 to 6 days. After fixation, root tips were hydrolyzed in $1 \mathrm{~N} \mathrm{HCl}$ at $60^{\circ} \mathrm{C}$ for $7 \mathrm{~min}$ and then placed in Feulgen stain for a minimum of $20 \mathrm{~min}$. Mitotic metaphase chromosome spreads were prepared by squashing root tips in aceto-carmine dye. The number of chromosomes in three to five nuclei then were determined visually using a light microscope.

Additional studies were conducted in 2004 to evaluate the seedling and field reaction of selected lines that displayed high levels of resistance to race NA67. Seedling tests were conducted using races NA1, NA8, NA16, NA28, NA55, and NA67 (10). These races were selected to provide diversity of virulence for all $P g$ genes. Lines were planted in cones and inoculated using previously described methods (8). Inoculated seedlings were incubated in the dark for $16 \mathrm{~h}$ at $20^{\circ} \mathrm{C}$ and near $100 \%$ relative humidity in a dew chamber. Plants then were moved to a greenhouse bench and covered with a plastic sheet for approximately $2 \mathrm{~h}$ to provide a period of slow drying and light $(250 \mu \mathrm{mol}$ $\left.\mathrm{m}^{-2} \mathrm{~s}^{-1}\right)$ to enhance infection. The plastic sheet was subsequently removed and plants maintained in the greenhouse at 20 $\pm 4^{\circ} \mathrm{C}$ with a 14-h light period supplemented with high-pressure sodium lighting. The infection type (IT) on seedlings of each line was assessed 12 to 14 days after inoculation using a 0 -to- 4 scale, where 0 to 2 was considered to indicate resistance and 3 to 4 susceptibility (21). Field tests were conducted at the CRC research station in Glenlea, MB in 2004. The oat cv. Triple Crown, which has no stem rust resistance genes, was used as the susceptible spreader and planted as described previously. The selected resistant lines were hand planted in 1-m rows 14 days later, parallel to the spreader rows. Triple Crown was inoculated with a mixture of races NA8, NA16, NA25, NA27, NA28, NA55, and NA67 (in equal proportions) at the flag leaf stage and 14 days later, and entries were evaluated for rust reaction as described above.

\section{RESULTS}

Stem rust infection was uniform across the NA67 nurseries each year, and was severe (70 to $90 \%$ severity, susceptible disease reaction) in 2001 and 2003 and moderate (40 to $50 \%$ severity, moderately susceptible to susceptible disease reaction) in 2002 on the susceptible check line AC Assiniboia. Stem rust reaction on the resis-

Table 1. Oat stem rust reaction of Avena spp. inoculated with Puccinia graminis f. sp. avenae race NA67 in field nurseries at Winnipeg, MB from 2001 to 2003

\begin{tabular}{|c|c|c|c|c|c|c|c|}
\hline \multirow[b]{3}{*}{ Species } & \multicolumn{7}{|c|}{ Number of accessions } \\
\hline & \multicolumn{4}{|c|}{ Disease reaction $^{x}$} & \multirow[b]{2}{*}{ No germination } & \multirow[b]{2}{*}{ Winter type } & \multirow[b]{2}{*}{ Total accessions } \\
\hline & $\mathbf{R}$ & MR & $\mathbf{I}$ & $\mathbf{S}$ & & & \\
\hline \multicolumn{8}{|l|}{ Diploid Avena spp. } \\
\hline A. atlantica B. R. Baum \& Fedak & $\ldots$ & $\ldots$ & $\ldots$ & 4 & $\ldots$ & 4 & 8 \\
\hline A. brevis Roth & 1 & $\ldots$ & 1 & 19 & $\ldots$ & $\ldots$ & 21 \\
\hline A. canariensis B. R. Baum et al. & $\ldots$ & $\ldots$ & 1 & 24 & 13 & 2 & 40 \\
\hline A. clauda Durieu & $\ldots$ & $\ldots$ & $\ldots$ & 25 & 17 & 17 & 59 \\
\hline A. damascena Rajh. \& B. R. Baum & $\ldots$ & $\ldots$ & $\ldots$ & 1 & 2 & $\ldots$ & 3 \\
\hline A. eriantha Durieu & $\ldots$ & $\ldots$ & 1 & 28 & 20 & 26 & 75 \\
\hline A. hirtula Lag. & $\ldots$ & $\ldots$ & $\ldots$ & 71 & 17 & 16 & 104 \\
\hline A. hispanica Ard. & $\ldots$ & $\ldots$ & $\ldots$ & 6 & 3 & 1 & 10 \\
\hline A. longiglumis Durieu & $\ldots$ & $\ldots$ & $\ldots$ & 16 & 2 & 8 & 26 \\
\hline A. lusitanica (Tab. Morais) B. R. Baum & $\ldots$ & $\ldots$ & 1 & 12 & 2 & 2 & 17 \\
\hline A. nuda L. & $\ldots$ & $\ldots$ & $\ldots$ & 19 & $\ldots$ & $\ldots$ & 19 \\
\hline A. strigosa Schreb. & 28 & 8 & 5 & 72 & 6 & $\ldots$ & 119 \\
\hline A. vaviloviana (Malzev) Mordv. & $\ldots$ & $\ldots$ & 9 & 90 & 2 & 1 & 102 \\
\hline A. ventricosa Balansa ex Coss. & $\ldots$ & $\ldots$ & $\ldots$ & $\ldots$ & $\ldots$ & 2 & 2 \\
\hline A. wiestii Steud. & $\ldots$ & $\ldots$ & $\ldots$ & 29 & 3 & 4 & 36 \\
\hline Total diploid & 29 & 8 & 18 & 416 & 87 & 83 & 641 \\
\hline \multicolumn{8}{|l|}{ Tetraploid Avena spp. } \\
\hline A. abyssinica Hochst. & $1^{\mathrm{y}}$ & $\ldots$ & 19 & 228 & 2 & 0 & 250 \\
\hline A. agadiriana B. R. Baum \& Fedak & $\ldots$ & $\ldots$ & $\ldots$ & 8 & $\ldots$ & 1 & 9 \\
\hline A. barbata Pott ex Link & 2 & 1 & 17 & 1,275 & 202 & 251 & 1,748 \\
\hline A. maroccana Gand. & $\ldots$ & $\ldots$ & 2 & 31 & 1 & $\ldots$ & 34 \\
\hline Total tetraploid & 3 & 1 & 38 & 1,542 & 205 & 252 & 2,041 \\
\hline \multicolumn{8}{|l|}{ Hexaploid Avena spp. } \\
\hline A. occidentalis Durieu & $\ldots$ & $\ldots$ & $\ldots$ & 47 & 1 & $\ldots$ & 48 \\
\hline A. sativa $\mathrm{L}$. & $2^{z}$ & $2^{z}$ & 6 & 933 & 14 & 34 & 991 \\
\hline A. sterilis L. & $1^{\mathrm{z}}$ & $1^{\mathrm{z}}$ & 9 & 6,922 & 321 & 490 & 7,744 \\
\hline Total hexaploid & 3 & 3 & 15 & 7,902 & 336 & 524 & 8,783 \\
\hline Grand total & 35 & 12 & 71 & 9,860 & 628 & 859 & 11,465 \\
\hline
\end{tabular}

${ }^{x} \mathrm{R}=$ resistant, $\mathrm{MR}=$ moderately resistant, $\mathrm{I}=$ intermediate, and $\mathrm{S}=$ susceptible.

$\mathrm{y}$ This highly resistant accession was subsequently determined to be diploid by cytogenetic analysis.

z These resistant accessions of $A$. sativa and A. sterilis were subsequently found to be either diploid or tetraploid by cytogenetic analysis. 
tant check line Pg- $a$ was low (5 to $10 \%$ severity, resistant disease reaction) in all nurseries. The reactions of the oat stem rust differential lines were indicative only of race NA67 (90 to $100 \%$ and susceptible on $\mathrm{Pg} 1, \mathrm{Pg} 2, \mathrm{Pg} 3, \mathrm{Pg} 4, \mathrm{Pg} 8, \mathrm{Pg} 9, \mathrm{Pg} 13$, and $P g 15 ; 5$ to $10 \%$ and intermediate for $P g 16 ; 1$ to $5 \%$ and resistant for $P g-a)$. Stem rust reactions for $P g 6$ ( 1 to $5 \%$ and resistant), $P g 10$ (25 to $50 \%$ and intermediate), $P g 11$ (5 to $10 \%$ and moderately resistant), $P g 12$ (50 to $70 \%$ and moderately susceptible), $P g 14$ (80 to $95 \%$ and susceptible), and $P g 17$ (70 to $90 \%$ and susceptible) to race NA67 also were noted.

Disease reactions of the Avena accessions to race NA67 are presented in Table 1. There were 628 accessions $(5.5 \%)$ that did not germinate and emerge and 859 $(7.5 \%)$ that were of winter growth habit and did not produce stem tissue for evaluation. This was more common in the diploid and tetraploid accessions than in the hexaploid accessions. There were high levels of resistance to race NA67 in 35 accessions, predominately found in the diploid species $A$. strigosa. There were 12 accessions rated as moderately resistant, mostly comprised again of A. strigosa. There were 71 accessions displaying inter- mediate resistance, mostly from $A$. abyssinica, A. barbata, A. sterilis, A. vaviloviana, and A. sativa. The majority $(9,860=$ $98.8 \%$ ) of accessions tested were susceptible to race NA67.

Four accessions classified as hexaploid or tetraploid displayed high levels of resistance to NA67 and, upon cytological analysis, most were found to be incorrectly classified as to species (Table 2). For example, chromosome counts of three highly resistant lines labeled as $A$. sterilis or $A$. sativa landraces verified them as diploid (1) or tetraploid (2); a resistant accession labeled A. abyssinica was diploid. Both resistant lines labeled as $A$. barbata were tetraploid. There were no lines identified in this study with high levels of resistance that were hexaploid upon cytological analysis.

Field and seedling reactions of NA67resistant lines to diverse races of $P$. graminis $\mathrm{f}$. $\mathrm{sp}$. avenae are presented in Table 3. Of 35 accessions showing high levels of resistance in previous field tests, 11 could not be evaluated due to insufficient seedstocks or winter growth habit. All other accessions, except CN 65882 and $\mathrm{CN} 81758$, were resistant (range of 5 to $20 \%$, resistant to moderately resistant) at the adult plant stage when inoculated with a mixture of isolates (NA8, NA16, NA25, NA27, NA28, NA55, and NA67). Stem rust reaction of the susceptible check Triple Crown was 50 to $60 \%$ severity and moderately susceptible. The seedling reaction of all lines, except CN 23731 and CN 26171, was susceptible to race NA1. In general, the seedling reaction of most lines was resistant to NA8, NA16, and NA67. NA28 and NA55 had the highest percentage (43 and $34 \%$, respectively) of virulence on the selected accessions. There were several accessions that were segregating for disease reaction and indicate heterogeneity in that accession for rust resistance. Similar patterns of disease response were noted across numerous accessions (e.g., CN 37279, CN 54877, CN 57130, CN 57739, CN 63840, CN 65326, and CN 65327; Saia group), while others, such as CN 58117, CN 65882, and CN 88865, had unique patterns of disease reaction.

\section{DISCUSSION}

Our study suggests that stem rust resistance in Avena spp. apparently is uncommon. From 9,978 accessions evaluated, only $47(0.5 \%)$ exhibited moderate to high levels of resistance to NA67 and only 71

Table 2. List of Avena accessions displaying high levels of resistance to Puccinia graminis f. sp. avenae race NA67 in field nurseries in Winnipeg, MB from 2001 to 2003

\begin{tabular}{|c|c|c|c|c|c|}
\hline CI/PI number & CN number & Other identifier & Avena sp. & Ploidy level & Origin \\
\hline Clav 3436 & & 4266 & A. brevis & Diploid & Brazil \\
\hline$\ldots$ & CN 21996 & CAV 2839 & A. strigosa & Diploid & Spain \\
\hline $\begin{array}{l}\cdots \\
\cdots\end{array}$ & CN 21997 & CAV 2840 & A. strigosa & Diploid & Spain \\
\hline$\ldots$ & CN 21998 & CAV 2841 & A. strigosa & Diploid & Spain \\
\hline$\ldots$ & CN 22000 & CAV 2843 & A. strigosa & Diploid & Spain \\
\hline$\ldots$ & CN 22001 & CAV 2844 & A. strigosa & Diploid & Spain \\
\hline$\ldots$ & CN 22002 & CAV 2845 & A. strigosa & Diploid & Uruguay \\
\hline CIav 7010 & CN 37279 & Saia selection & A. strigosa & Diploid & Brazil \\
\hline Clav 4639 & CN 54877 & Saia & A. strigosa & Diploid & Brazil \\
\hline CIav 5057 & CN 55115 & $\ldots$ & A. strigosa & Diploid & Former Soviet Union \\
\hline CIav 6858 & CN 56730 & $\ldots$ & A. strigosa & Diploid & Uruguay \\
\hline CIav 6956 & CN 56818 & Pg6 & A. strigosa & Diploid & Canada \\
\hline CIav 7280 & CN 57130 & $\ldots$ & A. strigosa & Diploid & United States \\
\hline Clav 8089 & CN 57739 & $\ldots$ & A. strigosa & Autotetraploid & United States \\
\hline CIav 9020 & CN 58072 & CD 3819 & A. strigosa & Diploid & Argentina \\
\hline CIav 9021 & CN 58073 & CD 3820 & A. strigosa & Diploid & Canada \\
\hline CIav 9066 & CN 58117 & CD 8088 & A. strigosa & Diploid & Canada \\
\hline CIav 6954 & CN 63840 & Saia & A. strigosa & Diploid & Brazil \\
\hline PI 291990 & CN 65326 & Saia 2 & A. strigosa & Diploid & Israel \\
\hline PI 291991 & CN 65327 & Saia 4 & A. strigosa & Diploid & Israel \\
\hline PI 304557 & CN 65882 & 4659 & A. strigosa & Diploid & United Kingdom \\
\hline PI 436103 & CN 81758 & 1 & A. strigosa & Diploid & Chile \\
\hline PI 436104 & CN 81759 & 35 & A. strigosa & Diploid & Chile \\
\hline PI 436105 & CN 81760 & 113 & A. strigosa & Diploid & Chile \\
\hline PI 436106 & CN 81761 & 117 & A. strigosa & Diploid & Chile \\
\hline PI 436110 & CN 81765 & 209 & A. strigosa & Diploid & Chile \\
\hline PI 436114 & CN 81769 & 302 & A. strigosa & Diploid & Chile \\
\hline PI 436117 & CN 81772 & 346 & A. strigosa & Diploid & Chile \\
\hline CIav 4747 & CN 88865 & WIR 5199 & A. strigosa & Diploid & Spain \\
\hline CIav 7233 & CN 57087 & $\ldots$ & A. abyssinica ${ }^{\mathrm{y}}$ & Diploid & Ethiopia \\
\hline$\ldots$ & CN 23731 & CAV 4599 & A. barbata & Tetraploid & Algeria \\
\hline & CN 26171 & CAV 7077 & A. barbata & Tetraploid & Spain \\
\hline PI 436031 & CN 81687 & $\ldots$ & A. sativa ${ }^{\mathrm{Z}}$ & Tetraploid & Chile \\
\hline PI 436080 & CN 81735 & $\ldots$ & A. sativa ${ }^{\mathrm{Z}}$ & Diploid & Chile \\
\hline Nevo 31-4 & $\ldots$ & $\ldots$ & A. sterilis $^{\mathrm{z}}$ & Tetraploid & Israel \\
\hline
\end{tabular}

${ }^{y}$ This species is tetraploid, but this accession was cytogenetically determined to be diploid and thus is misclassified (and unknown) to species.

${ }^{\mathrm{z}}$ These species are hexaploid, but these accessions were cytogenetically determined to be diploid or tetraploid and thus are misclassified (and unknown) to species. 
$(0.7 \%)$ were intermediate in reaction. This agrees with Martens and Dyck (15), who indicated that stem rust resistance in oat was relatively rare. In previous studies searching for stem rust resistance in wild and cultivated Avena spp. from the Middle East, only 6 accessions of 1,538 evaluated $(0.4 \%)$ displayed resistance to race NA27 (16). It appears that broadly effective stem rust resistance in cereals is uncommon. Fetch et al. (8) evaluated 116 accessions of Hordeum spontaneum from Israel for stem rust reaction to races $\mathrm{MCCF}$ and QCCJ and found high levels of resistance to be very rare $(<1 \%)$. Jin et al. (12) evaluated over 18,000 barley (H. vulgare) accessions for resistance to the virulent race QCC, and found only 13 that displayed high to intermediate resistance. In the very large gene pool of wheat (Triticum aestivum) and related wild species that have been examined extensively for stem rust resistance for over the last 50 years, only 45 numbered stem rust resistance genes have been described (19). However, many of these genes have been found to be ineffec- tive against predominant races and, thus, are not useful in agriculture (19). Extensive evaluations of hexaploid wheat for new $\mathrm{Sr}$ genes have been largely unsuccessful; therefore, the most likely sources would lie in related species (15).

In this study, the diploid species $A$. strigosa was clearly the best potential source of new stem rust resistance genes. Thirty-six accessions (30\%) of this species had moderate to high levels of resistance to NA67. However, the number of unique genes among the accessions may be low, because many had similar seedling infection type patterns in the seedling tests (Table 3). With the exception of the accessions from Spain, CN 55115, CN 58117, and $\mathrm{CN}$ 65882, all other diploid accessions had similar patterns and may contain the same gene or genes. These were mainly from South America and would have been introduced from their Mediterranean origin (20), which would explain their similar pattern of resistance. In contrast, accessions from Spain, the United Kingdom, and the former Soviet Union were diver- gent in their IT patterns to several races and indicate that several stem rust resistance genes could be present. Genetic studies using intercrosses among the Spanish accessions (CN 21996, CN 21997, CN 21998, CN 22000, and CN 22001) and CN 57130 are in progress to assess the number of different genes that they contain, and preliminary $\mathrm{F}_{2}$ data indicate that these accessions are allelic to Pg6 (T. Zegeye and T. Fetch, unpublished).

The potential of $A$. strigosa as a source of rust resistance genes has long been known (3). However, cross-compatibility between A. strigosa and A. sativa is extremely low (20). One technique that can be used to overcome this cross-incompatibility is to use autotetraploid derivatives of A. strigosa in crosses with A. sativa (24). Limited success in generating octoploid hybrids from $A$. strigosa $\times$ A. sativa $\mathrm{F}_{1}$ interspecific hybrids that were embryo rescued and treated with colchicine to double the chromosome complement also has been made (T. Zegeye and T. Fetch, unpublished). Another alternative would be

Table 3. Field reaction and seedling infection type (IT) of Avena accessions displaying high levels of resistance to Puccinia graminis f. sp. avenae race NA67

\begin{tabular}{|c|c|c|c|c|c|c|c|}
\hline \multirow[b]{2}{*}{ Accession } & \multirow[b]{2}{*}{ Field reaction $^{\mathrm{z}}$} & \multicolumn{6}{|c|}{ Seedling IT $^{\mathbf{y}}$} \\
\hline & & NA1 & NA8 & NA16 & NA28 & NA55 & NA67 \\
\hline CIav 3436 & 20 RMR & 4 & 0 & 0 & $0 ; 1^{-}$ & 0 & 0 \\
\hline CN 21996 & NP & 4 & 34 & $12^{-}$ & 34 & $; 2^{+}$and 24 & ;2 and 34 \\
\hline CN 21997 & 7 RMR & 34 & $23^{+}$ & 34 & $33^{+}$ & 34 & $12^{-}$ \\
\hline CN 21998 & NP & 34 & $\mathrm{X}^{-}$ & $0,12^{+} \mathrm{c}, 4$ & $23^{+}$ & 0 and 34 & $; 12^{-}, 4$ \\
\hline CN 22000 & NP & 34 & 14 & $; 1^{+}$ & 34 & $23^{-}$and $4 n$ & $11^{+}$ \\
\hline CN 22001 & NP & 4 & $2^{-}$and 34 & $; 2^{-}$ & 34 & $23^{-}$and 34 & $; 1^{+}$ \\
\hline CN 22002 & 10 RMR & 34 & 0 & 0 & 0 & 0 & 0 \\
\hline CN 37279 & NP & 4 & 0 & 0 & $; 1^{-}$ & 0 & 0 \\
\hline CN 54877 & 10 RMR & 4 & 0 & 0 & $; 1^{-}$ & 0 & 0 \\
\hline CN 55115 & NP & 4 & $22^{+}$and 34 & $22^{+}$ & 34 and $13^{-}$ & 23 & $0 ; 1$ \\
\hline CN 56730 & 10 RMR & 4 & 0 & 0 & 0 & 0 & 0 \\
\hline CN 56818 & 15 RMR & 4 & 0 & 0 & $; 1^{-}$ & 0 & $0 ; 1^{+}$ \\
\hline CN 57130 & 10 RMR & 4 & 0 & 0 & $; 1^{-}$ & 0 & 0 \\
\hline CN 57739 & 15 RMR & 4 & 0 & 0 & $; 1^{-}$ & 0 & 0 \\
\hline CN 58072 & 10 RMR & 4 & 0 & 0 & $; 1^{-}$and $3^{-}$ & 0 & 0 \\
\hline CN 58073 & $5 \mathrm{RMR}$ & 4 & 0 & 0 & $; 1^{-}$and $3^{-}$ & 0 & 0 \\
\hline CN 58117 & 15 RMR & 4 & 0 and 34 & $12^{+}$and 24 & 34 & 13 & $; 1$ and 34 \\
\hline CN 63840 & NP & 34 & 0 & 0 & 0 & 0 & 0 \\
\hline CN 65326 & 10 RMR & 34 & 0 & 0 & 0 & 0 & 0 \\
\hline CN 65327 & 15 RMR & 4 & 0 & 0 & $0 ; 1^{-}$ & 0 & 0 \\
\hline CN 65882 & $20 \mathrm{I}$ & 34 & $12^{-}$ & $23^{+}$ & $22^{-}$ & $12^{-}$and $23^{+}$ & $0 ; 1$ \\
\hline CN 81758 & $30 \mathrm{I}$ & 4 & 0 & 0 & $0 ; 1^{-}$and $3^{-}$ & 0 & 0 \\
\hline CN 81759 & 15 RMR & 4 & 0 & 0 & $0 ; 1^{-}$ & 0 & 0 \\
\hline CN 81760 & 15 RMR & 34 & 0 & 0 & $0 ; 1^{-}$ & 0 & 0 \\
\hline CN 81761 & 20 RMR & 4 & 0 & 0 & $0 ; 1^{-}$and $3^{-}$ & 0 & 0 \\
\hline CN 81765 & 10 RMR & 4 & 0 & 0 & $0 ; 1^{-}$ & 0 & 0 \\
\hline CN 81769 & 15 RMR & 4 & 0 & 0 & $0 ; 1^{-}$ & 0 & 0 \\
\hline CN 81772 & 15 RMR & 4 & 0 & 0 & $0 ; 1^{-}$ & 0 & 0 \\
\hline CN 88865 & NP & 4 & 34 & 4 & 34 & $0 ;$ and $12^{-}$ & $; 1$ and 4 \\
\hline CN 57087 & NP & 4 & 0 & 0 & 0 ; and $3^{-}$ & $0 ; 1^{-}$ & 0 \\
\hline CN 23731 & Winter & $0 ; 1^{-}$ & $; 1^{-}$ & $0 ; 1^{-}$ & $0 ; 1$ & 4 & $0 ; 1$ \\
\hline CN 26171 & 10 RMR & $0 ; 1^{-}$and 4 & 0 & $; 1^{-}$ & $11^{+}$ & 4 & 0 \\
\hline CN 81687 & 5 RMR & 4 & 0 & 0 & $0 ; 1^{-}$ & 0 & 0 \\
\hline CN 81735 & 20 RMR & 4 & 0 & 0 & $0 ; 1$ & 0 & 0 \\
\hline Nevo 31-4 & NP & $33^{+}$ & $0 ; 1^{-}$ & 4 & 34 & 4 & 4 \\
\hline
\end{tabular}

y Seedling IT is based on a 0-to-4 scale where $0 ;, 1$, and 2 are indicative of a resistant reaction and 3 or 4 of susceptibility (21). Plus (+) and minus (-) signs are indicative of slightly larger or slightly smaller pustules, respectively, for each type. The letter "c" denotes chlorosis at the pustule margin. Virulence diversity of the NA races was previously described $(10,17)$.

${ }^{\mathrm{z}}$ Field reaction is the percent severity and the infection response (RMR $=$ resistant to moderately resistant; $\mathrm{I}=$ intermediate resistant) to a mixture of isolates (NA8, NA16, NA25, NA27, NA28 NA55, and NA67 in equal proportion) in a 2004 rust nursery at Glenlea, MB, Canada. NP = not planted due to insufficient seed, Winter $=$ winter growth habit. 
to use genetic engineering techniques to clone and insert the diploid gene into the desired parent, similar to what has been done with Rpgl in barley (11).

The next best sources of stem rust resistance appear to be in the tetraploid species A. abyssinica and A. barbata. However, in this study, stem rust resistance was predominately at intermediate levels and, even if successfully transferred to A. sativa, could reduce yield or introduce undesirable phenotypes (9). The seedling IT patterns in the two A. barbata lines (CN 23731 and $\mathrm{CN}$ 26171) are identical with the gene $P g 16$; thus, they may be the same gene. $P g 16$, derived from $A$. barbata line D-203, has been introgressed into a hexaploid background (2) and confers resistance to all but one race (NA55) of oat stem rust reported to occur in North America (10). However, this gene appears to lose effectiveness at temperatures exceeding $27^{\circ} \mathrm{C}$ (4) and has yielded about $10 \%$ less in breeding lines where the gene was introgressed (J. Mitchell Fetch, unpublished). The tetraploid line CN 81687 has a seedling IT pattern different than Pgl6 (resistant to NA55) and may be a novel gene. Attempts to generate pentaploid hybrids from crosses of CN $81687 \times$ Sun II $A$. sativa oat and allelism tests to $P g 16$ currently are in progress at the CRC in Winnipeg.

In summary, the vast majority $(98.8 \%)$ of all lines evaluated for reaction to race NA67 were susceptible. There were no hexaploid accessions identified with moderate to high levels of resistance to NA67 from 7,923 accessions tested. Four accessions listed as A. sativa and two as A. sterilis that displayed high or moderate levels of resistance later were found to be either diploid or tetraploid by cytological examination. Of 642 A. sterilis accessions obtained from the University of Haifa, Israel, only one (Nevo [Tel Megiddo] 31-4) displayed a high level of resistance and later was found to be tetraploid. In contrast to Martens (14), it appears that the prospect of finding novel effective oat stem rust resistance genes from hexaploid sources of germ plasm is unlikely. Nevertheless, the diploid and tetraploid sources of oat stem rust resistance identified in this study should be of value to plant breeding efforts. Successful transfer of resistance from lower ploidy to the hexaploid state is the major obstacle to be overcome.

\section{ACKNOWLEDGMENTS}

We thank H. Bockelman (USDA-ARS), A. Diedrichsen (PGRC), and E. Nevo (University of Haifa) for graciously providing seed for the NA67 evaluation; and C. Wolfe, K. Dunsmore, and W. Mayert for providing technical assistance.

\section{LITERATURE CITED}

1. Anonymous. 2002. Canada Grains Council Statistical Handbook, ISSN 1201-5679. B. Tjaden Lepp, ed. Winnipeg, Canada.

2. Brown, P. D., Forsberg, R. A., McKenzie, R. I. H., and Martens, J. W. 1986. The use of disomic alien addition lines in the transfer of oat stem rust resistance to hexaploid oats. Pages 16-20 in: Proc. Int. Oats Conf., 2nd. D. A. Lawes and H. Thomas, eds. Dordrecht, The Netherlands.

3. Dyck, P. L. 1966. Inheritance of stem rust resistance and other characteristics in diploid oats, Avena strigosa. Can. J. Genet. Cytol. 8:444-450.

4. Fetch, T. 2003. Temperature sensitivity of oat stem rust resistance genes. Can. J. Plant Pathol. 25:423-424.

5. Fetch, T., and Dunsmore, K. 2003. Stem rusts of cereals in western Canada in 2002. Can. Plant Dis. Surv. 83:76-77

6. Fetch, T., and Dunsmore, K. 2004. Stem rusts of cereals in western Canada in 2003. Can. Plant Dis. Surv. 84:52.

7. Fetch, T. G., Jr., Gold, J., and Nevo, E. 2002. Evaluation of wild oat germplasm for stem rust resistance. Page 195 in: Proc. Intl. Congr. Plant Pathol., 8th. Vol. 2. D. Swain and S. Zydenbos, eds. Christchurch, NZ. Lincoln University Press, Canterbury, NZ.

8. Fetch, T. G., Jr., Steffenson, B. J., and Nevo, E. 2003. Diversity and sources of multiple disease resistance in Hordeum spontaneum. Plant Dis. 87:1439-1448.

9. Frey, K. J. 1991. Genetic resources of oats. Pages 15-24 in: Use of Plant Introductions in Cultivar Development. H. L. Shands and L. E. Wiesner, eds. Crop Science of America, Inc. Madison, WI.

10. Harder, D. E. 1994. Identification of new races of Puccinia graminis f. sp. avenae. Plant Dis. 78:367-368.
11. Horvath, H., Rostoks, N., Brueggeman, R Steffenson, B., von Wettstein, D., and Kleinhofs, A. 2003. Genetically engineered stem rust resistance in barley using the Rpgl gene. Proc. Natl. Acad. Sci. USA 100:364-369.

12. Jin, Y., Steffenson, B. J., and Fetch, T. G., Jr 1994. Sources of resistance to pathotype QCC of Puccinia graminis f. sp. tritici in barley. Crop Sci. 34:285-288.

13. Martens, J. W. 1978. Stem rust of oats in Canada in 1977. Can. Plant Dis. Surv. 58:51-52.

14. Martens, J. W. 1985. Stem rust of oats. Pages 103-129 in: The Cereal Rusts: Volume II: Diseases, Distribution, Epidemiology, and Control. A. P. Roelfs and W. R. Bushnell, eds. Academic Press, New York.

15. Martens, J. W., and Dyck, P. L. 1989. Genetics of resistance to rust in cereals from a Canadian perspective. Can. J. Plant Pathol. 11:78-85.

16. Martens, J. W., McKenzie, R. I. H., and Harder, D. E. 1980. Resistance to Puccinia graminis avenae and $P$. coronata avenae in the wild and cultivated Avena populations of Iran, Iraq, and Turkey. Can. J. Genet. Cytol. 22:641649.

17. Martens, J. W., Roelfs, A. P., McKenzie, R. I. H., Rothman, P. G., Stuthman, D. D., and Brown, P. D. 1979. System of nomenclature for pathotypes of Puccinia graminis f. sp. avenae. Phytopathology 69:293-294.

18. McCallum, B. D., Harder, D. E., and Dunsmore, K. 2000. Stem rusts on wheat, barley, and oat in Canada in 1998. Can. J. Plant Pathol. 22:23-28.

19. McIntosh, R. A., Wellings, C. R., and Park, R. F. 1995. Pages 83-148 in: Wheat Rusts: An Atlas of Resistance Genes. A. Cloud-Guest, ed. Commonwealth Scientific and Industrial Research Organization Publications, Melbourne, Australia.

20. Rajhathy, T., and Thomas, H. 1974. Cytogenetics of Oats. Misc. publ. 2. A. Wilkes, ed The Genetics Society of Canada, Ottawa, Canada.

21. Roelfs, A. P., Singh, R. P., and Saari, E. E. 1992. Rust Diseases of Wheat: Concepts and Methods of Disease Management. CIMMYT, Mexico.

22. Small, E. 1999. New crops for Canadian agriculture. Pages 15-52 in: Perspectives on New Crops and New Uses. J. Janick, ed.. ASHS Press, Alexandria, VA

23. Zadoks, J. C., Chang, T. T., and Konzak, C. F. 1974. A decimal code for the growth stages of cereals. Weed Res. 14:415-421.

24. Zillinsky, F. J., and Derick, R. A. 1960. Crown rust resistant derivatives from crosses between autotetraploid Avena strigosa and A. sativa. Can. J. Plant Sci. 40:366-370. 